\title{
Contemporary results of surgery in acute type $A$ aortic dissection: The International Registry of Acute Aortic Dissection experience
}

\author{
Santi Trimarchi, MD \\ Christoph A. Nienaber, MD \\ Vincenzo Rampoldi, MD \\ Truls Myrmel, MD \\ Toru Suzuki, MD \\ Rajendra H. Mehta, MD \\ Eduardo Bossone, MD \\ Jeanna V. Cooper, MS \\ Dean E. Smith, PhD \\ Lorenzo Menicanti, MD \\ Alessandro Frigiola, MD \\ Jae K. Oh, MD \\ Michael G. Deeb, MD \\ Eric M. Isselbacher, MD \\ Kim A. Eagle, MD \\ On behalf of the International Registry of Acute Aortic Dissection Investigators*
}

Supported in part by grants from the University of Michigan Faculty Group Practice and the Varbedian Fund for Aortic Research.

Read at the Eighty-fourth Annual Meeting of The American Association for Thoracic Surgery, Toronto, Ontario, Canada, April 25-28, 2004.

Received for publication Jan 16, 2004; revisions received Aug 4, 2004; accepted for publication Sept 3, 2004

Address for reprints: Santi Trimarchi, MD, Istituto Policlinico S Donato, via Morandi 30, 20097 S Donato Milanese, Italy (Email: satrimarchi@yahoo.it).

*International Registry of Acute Aortic Dissection investigators are listed in Appendix 1 .

J Thorac Cardiovasc Surg 2005;129:112-22

$0022-5223 / \$ 30.00$

Copyright $\odot 2005$ by The American Association for Thoracic Surgery

doi:10.1016/j.jtcvs.2004.09.005
Background: Surgical mortality for acute type A aortic dissection reported in different experiences from single centers or surgeons varies from $7 \%$ to $30 \%$. The International Registry of Acute Aortic Dissection, collecting patients from 18 referral centers worldwide, identifies a preoperative risk stratification scheme and a real average surgical mortality for acute type A aortic dissection in the current era.

Methods: A comprehensive analysis was completed of 290 clinical variables and their relationship to surgical outcomes in 526 of 1032 patients enrolled in the International Registry of Acute Aortic Dissection from 1996 through 2001. Extracted cases, categorized according to risk profile, were defined as unstable (group I) in the presence of cardiac tamponade; shock; congestive heart failure; cerebrovascular accident; stroke; coma; myocardial ischemia, infarction, or both; electrocardiograms with new Q waves or ST elevation; acute renal failure; or mesenteric ischemia-infarction at the time of the operation. Outside of an unstable condition, patients were categorized as stable (group II).

Results: The overall in-hospital mortality was $25.1 \%$. Mortality in group I was $31.4 \%$ compared with $16.7 \%$ in group II $(P<.001)$. Independent preoperative predictors of operative mortality were history of aortic valve replacement (odds ratio $=3.12$ ), migrating chest pain (odds ratio $=2.77$ ), hypotension as sign of acute type A aortic dissection (odds ratio $=1.95$ ), shock or tamponade (odds ratio $=2.69$ ), preoperative cardiac tamponade (odds ratio $=2.22$ ), and preoperative limb ischemia (odds ratio $=$ 2.10).

Conclusions: The International Registry of Acute Aortic Dissection experience confirms that patient selection plays an important role in determining surgical outcomes in patients with acute type A aortic dissection. Knowledge of significant risk factors for operative mortality can contribute to better management and a more defined risk assessment in patients affected by acute type A aortic dissection. 


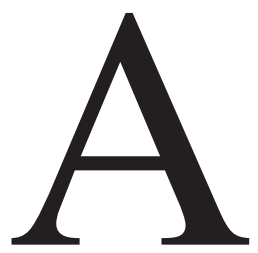

cute proximal aortic dissection is one of the most serious cardiovascular conditions and is associated with morbidity and mortality that has not changed in recent decades. ${ }^{1-9}$ Emergency surgical treatment is aimed to avoid lethal complications from complete rupture, pericardial tamponade, or coronary obstruction. Despite improved surgical techniques and perioperative care, operative mortality remains high, between $15 \%$ and $30 \% .^{1-9}$ Advances in understanding the pathophysiology of dissection and its variants and the proliferation of improved diagnostic and therapeutic procedures have raised expectations for better outcomes. The relationship between preoperative risk factors and mortality has been studied recently but only in small groups of patients collected over

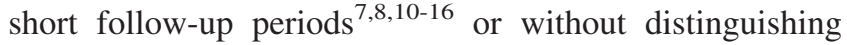
type A from type B dissection ${ }^{10,13,14,16,17}$ or acute from chronic cases. $7,11,14,16,17$ The International Registry of Acute Aortic Dissection (IRAD) represents a unique opportunity to study large groups of consecutive patients affected by aortic dissection collected in 18 large referral centers worldwide. We completed a comprehensive analysis of 290 clinical variables and their relationship to surgical outcomes. The aim of this analysis was to identify important corollaries of surgical outcomes in acute type A aortic dissection and to create a preoperative risk stratification scheme to improve medical and surgical treatment.

\section{Methods}

\section{Patient Selection and Data Collection}

The IRAD has previously been described. ${ }^{9}$ One thousand thirtytwo consecutive patients with acute aortic dissection were enrolled at 18 large tertiary centers in 6 countries between January 1, 1996, and December 31, 2001. The aim of the IRAD is to identify patterns of clinical signs and presentation, diagnostic and therapeutic management, and outcomes of patients with acute aortic dissection prospectively followed from presentation or retrospectively followed from hospital records. Data were collected by using a standardized data form with 290 clinical variables, including patient demographics, history, clinical presentation, physical findings, imaging studies, medical and surgical management, inhospital mortality, and adverse events. Completed data forms were forwarded to the coordinating center at the University of Michigan. Data forms were reviewed for analytic internal validity and scanned electronically into an Access database. For this analysis, 647 potential candidates for surgical intervention with proximal aortic dissection were analyzed.

\section{Data Analysis}

Summary statistics were presented as frequencies and percentages, means $\pm \mathrm{SD}$, or medians and interquartile ranges. Missing data were not defaulted to negative, and denominators reflect only actual reported cases. Associations of death among nominal variables were compared by using the $\chi^{2}$ test or the 2-sided Fisher exact test. Bivariate comparisons of continuous variables were compared with the Student $t$ test or the Wilcoxon rank sum test. Iterative logistic modeling was performed for in-hospital mortality by using the likelihood ratio test for model selection. Initial modeling implemented elements marginally suggestive of an unadjusted association to in-hospital mortality $(P<.20)$. Variables were reviewed for clinical significance before testing. Diagnostic routines (Hosmer-Lemeshow test for lack of fit, change in deviance and residuals, and leverage indicators) were used on final model selection.

Extracted cases were also categorized according to risk profile; very high-risk patients were defined as preoperatively showing and/or presenting to surgical intervention with cardiac tamponade; shock; congestive heart failure; cerebrovascular accident; stroke; coma; myocardial ischemia, infarction, or both; electrocardiograms (ECGs) with new Q waves or ST elevation; acute renal failure; or mesenteric ischemia-infarction and were considered unstable (group I). Outside of an unstable setting, patients were categorized as stable and at moderate risk (group II). We compared presenting features and outcomes for group I (unstable) versus group II (stable) by using the $\chi^{2}$ test or the Student $t$ test. SAS 8.2 (SAS Institute, Cary, NC) and SPSS 11.5 (SPSS Inc, Chicago, Ill) were used for the analyses.

\section{Results}

\section{Patient Population}

Of 1032 consecutive patients with acute aortic dissection enrolled between January 1, 1996, and December 31, 2001, $647(62.7 \%)$ had type A dissection. Of these, 121 (18.7\%) patients were treated medically for a variety of reasons, such as advanced age (23 [23.5\%] patients), severe comorbid illness (65 [66.3\%] patients), intramural hematoma (16 [13.7\%] patients), or refusal of any surgical intervention (18 [18.4\%] patients). A total of 526 patients underwent operations for acute type A aortic dissection and were included in this analysis. Their mean age was $60 \pm 14$ years, with male predominance $(70 \%)$. Of these, 375 (72.5\%) patients had been transferred to an IRAD center from a referral hospital for definitive treatment. Among surgical patients, Marfan syndrome was present in $6.0 \%$, and $7.5 \%$ of patients had prior myocardial infarction. Hypertension was present in $68.9 \%$ of patients, atherosclerosis in $26.9 \%$, and diabetes in $3.2 \%$. A bicuspid aortic valve was noted in $4.9 \%$ of patients. Prior aortic dissection or aortic aneurysms were seen in $2.7 \%$ and $10 \%$ of patients, respectively. Prior cardiac surgery was noted in $17.2 \%$, with aortic valve replacement in $4.4 \%$; coronary artery bypass grafting (CABG) in $6.3 \%$; aortic replacement for aneurysm, dissection, or both in 5\%; and mitral valve surgery in $0.4 \%$. In $28(5.8 \%)$ patients iatrogenic dissection was suggested as a complication of cardiac surgery or cardiac catheterization (Table 1).

\section{Presenting Signs and Symptoms}

The abrupt onset of pain was observed in $85.5 \%$ of patients: chest pain was present in $81.6 \%$, back pain in $45.8 \%$, and abdominal pain in $22 \%$. The initial ECG appeared normal in 
TABLE 1. Demographics and history of surgical patients with acute type A aortic dissection

\begin{tabular}{|c|c|c|c|c|}
\hline Variable & $\begin{array}{c}\text { Overall } \\
(\mathrm{n}=526)\end{array}$ & $\begin{array}{l}\text { Survived } \\
(\mathrm{n}=394)\end{array}$ & $\begin{array}{c}\text { Dead } \\
(n=132)\end{array}$ & $P$ value \\
\hline $\mathrm{n}(\%)$ & $526(100.0)$ & $394(74.9)$ & $132(25.1)$ & - \\
\hline Age (mean $\pm S D$ ), y & $59.7 \pm 13.6$ & $58.7 \pm 13.2$ & $62.5 \pm 14.2$ & .005 \\
\hline Age $\geq 70$ y & $139(26.5)$ & $91(23.2)$ & $48(36.4)$ & .003 \\
\hline Female sex & $158(30.1)$ & $108(27.5)$ & $50(37.9)$ & .02 \\
\hline Referred to IRAD center & $375(72.5)$ & $283(73.3)$ & $92(70.2)$ & .49 \\
\hline Marfan syndrome & $31(6.0)$ & $25(6.4)$ & $6(4.8)$ & .51 \\
\hline Hypertension & $354(68.9)$ & $268(69.3)$ & $86(67.7)$ & .75 \\
\hline Atherosclerosis & $138(26.9)$ & $100(25.8)$ & $38(30.2)$ & .34 \\
\hline Known aortic aneurysm & $51(10.0)$ & $39(10.1)$ & $12(9.7)$ & .90 \\
\hline Prior aortic dissection & $14(2.7)$ & $14(3.6)$ & $0(0.0)$ & .03 \\
\hline Diabetes mellitus & $16(3.2)$ & $13(3.4)$ & $3(2.4)$ & .77 \\
\hline Prior cardiac surgery & $76(17.2)$ & $53(15.9)$ & $23(21.1)$ & .21 \\
\hline Aortic valve replacement & $22(4.4)$ & $13(3.5)$ & $9(7.4)$ & .07 \\
\hline Aortic aneurysm and/or dissection & $25(5.0)$ & $18(4.8)$ & $7(5.8)$ & .66 \\
\hline Coronary artery bypass surgery & $31(6.3)$ & $21(5.6)$ & $10(8.1)$ & .32 \\
\hline Mitral valve surgery & $2(0.4)$ & $2(0.5)$ & $0(0.0)$ & $>.99$ \\
\hline latrogenic & $28(5.8)$ & $19(5.2)$ & $9(7.8)$ & .30 \\
\hline Bicuspid aortic valve & $15(4.9)$ & $12(5.2)$ & $3(3.9)$ & $>.99$ \\
\hline
\end{tabular}

IRAD, International Registry of Acute Aortic Dissection.

$31.0 \%$, with signs of myocardial ischemia in $19.9 \%$ and myocardial infarction with new Q waves or ST elevations in 6.0\%. A pulse deficit was present in 139 (31.0\%) patients, and heart failure was present in $5.4 \%$. The acute manifestation of aortic dissection included syncope in $19.4 \%$ and neurologic symptoms in $13.6 \%$, with cerebral ischemia in $5.7 \%$ of patients (Table 2). Preoperative hypertension appeared at presentation in $32.4 \%$ of patients and hypotension in $17.6 \%$, and shock or tamponade was diagnosed in $16.1 \%$ before the operation. Hemodynamic status was documented on arrival in the referral hospital and at the time of the operation (Table 3 ).

\section{Diagnostic Evaluation}

The diagnosis of acute type A aortic dissection was made with one or more imaging methods in the vast majority of cases, including transesophageal echocardiography in $79.3 \%$, computed tomography in $68.1 \%$, aortography in $19 \%$, and magnetic resonance imaging in $4.8 \%$. Chest radiography showed a widened mediastinum in $61.5 \%$ of patients, whereas no abnormalities were noted on chest radiography in $14.3 \%$. Tomographic imaging revealed intramural hematoma in $5.4 \%$ of patients, aortic regurgitation in $62.6 \%$, pericardial effusion in $46.3 \%$, and coronary artery involvement in $14.2 \%$. A proximal intimal tear was identified in the aortic root in $39.0 \%$ of patients, in the ascending aorta in $54.7 \%$, and in the aortic arch in $3.8 \%$ (Table 4). The mean diameter of the aortic annulus was $30 \mathrm{~mm}$, the aortic root was $44 \mathrm{~mm}$, the sinotubular junction was $41 \mathrm{~mm}$, the ascending aorta was $52 \mathrm{~mm}$, and the aortic arch was $37 \mathrm{~mm}$.

\section{Surgical Strategy}

A standard median sternotomy and total cardiopulmonary bypass were performed in all patients. The ascending aorta was replaced in $463(91.9 \%)$ patients, the aortic root in 135 (31.5\%) patients, the partial arch in 110 $(23.2 \%)$ patients, the complete arch in $59(12.2 \%)$ patients, and the descending aorta in $18(3.7 \%)$ patients. The aortic valve, root, and ascending aorta were replaced in $66(13.9 \%)$ patients by use of a composite aortic valve graft. An open procedure with hypothermic circulatory arrest was used in 91\% (455 patients) of patients, with antegrade cerebral perfusion in $256(52.2 \%)$ patients. Overall, the aortic valve was replaced in $111(23.1 \%)$ patients, and simultaneous CABG was necessary in 78 (16.1\%) patients; in-hospital reoperation was required in $61(12.8 \%)$ patients (Table 5). The mean interval between onset of symptoms and surgical intervention was 79.3 hours, with 37.9 hours in nonsurvivors and 93.0 hours in in-hospital survivors $(P<.001)$. The mean interval between the onset of symptoms and surgical intervention in unstable patients (group I) was 62.9 hours versus 105.1 hours in stable patients (group II, $P=.05$ ). The median interval between confirmed diagnosis and surgical intervention was 3.4 hours in the unstable (group I) patients and 5.0 hours in stable patients (group II, $P=.02$ ). Surgical intervention was noted to be delayed for a number of reasons, including the need to obtain confirmatory imaging studies, the need to perform coronary angiography, a delay until the surgeon or operating room became available, or resolution of a comorbid medical 
TABLE 2. Presenting symptoms and signs of surgical patients with acute type $A$ aortic dissection

\begin{tabular}{|c|c|c|c|c|}
\hline Variable & $\begin{array}{c}\text { Overall } \\
(\mathrm{n}=526)\end{array}$ & $\begin{array}{l}\text { Survived } \\
\text { (n }=394)\end{array}$ & $\begin{array}{c}\text { Dead } \\
\text { (n }=132)\end{array}$ & $P$ value \\
\hline Any pain reported & $470(89.4)$ & $354(89.8)$ & $116(87.9)$ & .53 \\
\hline Abrupt onset & $426(85.5)$ & $322(85.4)$ & $104(86.0)$ & .88 \\
\hline Chest pain & $416(81.6)$ & $316(82.7)$ & $100(78.1)$ & .25 \\
\hline Abdominal pain & $110(22.0)$ & $82(21.9)$ & $28(22.2)$ & .94 \\
\hline Severity of pain: severe or worst ever & $378(91.3)$ & $278(89.4)$ & $100(97.1)$ & .02 \\
\hline Migrating pain & $69(14.2)$ & $44(12.1)$ & $25(20.5)$ & .02 \\
\hline Syncope & $98(19.4)$ & $69(18.2)$ & $29(23.2)$ & .22 \\
\hline Any pulse deficit & $139(31.0)$ & $90(26.9)$ & $49(43.0)$ & .001 \\
\hline Congestive heart failure & $27(5.4)$ & $25(6.7)$ & $2(1.6)$ & .03 \\
\hline New neurologic deficit & $68(13.6)$ & $45(11.8)$ & $23(19.5)$ & .03 \\
\hline ECG normal with no abnormalities noted & $153(31.0)$ & $127(33.9)$ & $26(22.0)$ & .02 \\
\hline ECG with findings of left ventricular hypertrophy & $101(21.6)$ & $79(22.2)$ & $22(19.8)$ & .60 \\
\hline ECG with findings of myocardial ischemia & $94(19.9)$ & $64(17.8)$ & $30(26.8)$ & .04 \\
\hline $\begin{array}{l}\text { ECG with findings of myocardial infarction, new } 0 \text { waves, } \\
\text { or ST deviation }\end{array}$ & $28(6.0)$ & $16(4.5)$ & $12(10.9)$ & .01 \\
\hline Preoperative myocardial ischemia & $52(10.4)$ & $35(9.3)$ & $17(13.9)$ & .14 \\
\hline Preoperative myocardial infarction & $18(3.6)$ & $10(2.7)$ & $8(6.6)$ & .06 \\
\hline Mesenteric ischemia-infarction & $10(2.0)$ & $8(2.1)$ & $2(1.6)$ & $>.99$ \\
\hline Limb ischemia & $48(9.7)$ & $29(7.8)$ & $19(15.8)$ & .009 \\
\hline Acute renal failure & $22(4.4)$ & $16(4.3)$ & $6(5.0)$ & .75 \\
\hline Cardiac tamponade & $78(15.7)$ & 44 (11.8) & $34(27.6)$ & $<.0001$ \\
\hline
\end{tabular}

ECG, Electrocardiogram.

TABLE 3. Preoperative hemodynamic status of surgical patients with acute type A aortic dissection

\begin{tabular}{|c|c|c|c|c|}
\hline Variable & $\begin{array}{c}\text { Overall } \\
(n=526)\end{array}$ & $\begin{array}{l}\text { Survived } \\
(n=394)\end{array}$ & $\begin{array}{c}\text { Dead } \\
(n=132)\end{array}$ & $P$ value \\
\hline \multicolumn{5}{|l|}{ Blood pressure at presentation } \\
\hline Hypertension (SBP >150 mm Hg) & $160(32.4)$ & $128(34.2)$ & $32(26.7)$ & .12 \\
\hline Normotension (SBP 100-149 mm Hg) & $213(42.9)$ & $176(46.9)$ & $37(30.6)$ & .002 \\
\hline Hypotension (SBP <100 mm Hg) & $88(17.6)$ & $50(13.3)$ & $38(30.4)$ & $<.0001$ \\
\hline Shock or tamponade (SBP $\leq 80 \mathrm{~mm} \mathrm{Hg}$ ) & $82(16.1)$ & $47(12.3)$ & $35(27.6)$ & $<.0001$ \\
\hline \multicolumn{5}{|l|}{ Blood pressure after hospitalization } \\
\hline In-hospital preoperative hypotension (SBP $<100 \mathrm{~mm} \mathrm{Hg}$ ) & $123(24.7)$ & $73(19.5)$ & $50(40.7)$ & $<.0001$ \\
\hline Hypotension from onset to the time of the operation & $213(40.6)$ & $123(31.3)$ & $90(68.2)$ & $<.0001$ \\
\hline \multicolumn{5}{|l|}{ Hemodynamics at the time of the operation } \\
\hline Hypotension-shock at the time of the operation & $153(31.0)$ & $79(21.4)$ & $74(59.2)$ & $<.001$ \\
\hline Normotension at the time of the operation & $262(53.9)$ & $219(60.5)$ & $43(34.7)$ & $<.001$ \\
\hline LV dysfunction at the time of the operation & $63(13.0)$ & $34(9.3)$ & $29(24.2)$ & $<.001$ \\
\hline RV dysfunction at the time of the operation & $31(6.4)$ & $10(2.8)$ & $21(17.5)$ & $<.001$ \\
\hline
\end{tabular}

$S B P$, Systolic blood pressure; $L V$, left ventricular; $R V$, right ventricular.

condition. Delay ( $>24$ hours) was noted in $111(21.4 \%)$ patients, of whom 92 survived.

\section{Hospital Outcomes}

The overall in-hospital mortality was $25.1 \%$. In group I mortality was $31.4 \%$ compared with $16.7 \%$ in group II $(P$ $<.001)$. Mortality in patients with surgical treatment delayed beyond 24 hours was $17.1 \%$. Causes of death were neurologic $(13.8 \%)$, visceral ischemia (12.1\%), aor- tic rupture $(32.8 \%)$, tamponade $(3.4 \%)$, and nonspecified (41.9\%). Univariate predictors of death after surgical intervention $(P<.05)$ were age of 70 years or greater; female sex; prior aortic dissection; presentation with severe or worst ever pain; migrating pain; a widened mediastinum on chest radiography; hypotension (systolic blood pressure $<100 \mathrm{~mm} \mathrm{Hg}$ ) or shock (systolic blood pressure $<80 \mathrm{~mm} \mathrm{Hg}$ ) before the operation; myocardial ischemia, infarction, or both with new $\mathrm{Q}$ waves; presence 
TABLE 4. Diagnostic methods and evidences of surgical patients with acute type A aortic dissection

\begin{tabular}{|c|c|c|c|c|}
\hline Variable & $\begin{array}{c}\text { Overall } \\
(n=526)\end{array}$ & $\begin{array}{l}\text { Survived } \\
(\mathrm{n}=394)\end{array}$ & $\begin{array}{c}\text { Dead } \\
(n=132)\end{array}$ & $P$ value \\
\hline Transesophageal echocardiography & $417(79.3)$ & $313(79.4)$ & $104(78.8)$ & .87 \\
\hline Computed tomography & $358(68.1)$ & $274(69.5)$ & $84(63.6)$ & .21 \\
\hline Aortography & $100(19.0)$ & $83(21.1)$ & $17(12.9)$ & .04 \\
\hline Magnetic nuclear resonance & $25(4.8)$ & $22(5.6)$ & $3(2.3)$ & .12 \\
\hline No abnormalities observed at chest radiography & $65(14.3)$ & $55(16.0)$ & $10(8.9)$ & .06 \\
\hline Widened mediastinum at chest radiography & $279(61.5)$ & $199(58.2)$ & $80(71.4)$ & .01 \\
\hline Intramural hematoma & $28(5.4)$ & $19(4.9)$ & $9(6.9)$ & .37 \\
\hline Aortic valve regurgitation & $300(62.6)$ & $227(63.2)$ & $73(60.8)$ & .64 \\
\hline Pericardial effusion & $228(46.3)$ & $170(45.7)$ & $58(48.3)$ & .62 \\
\hline Coronary artery involvement & $57(14.2)$ & $44(14.3)$ & $13(13.8)$ & .90 \\
\hline Intimal tear evidenced in ascending aorta & $186(41.6)$ & $145(43.2)$ & $41(36.9)$ & .25 \\
\hline Intimal tear evidenced in aortic arch & $26(5.8)$ & $18(5.4)$ & $8(7.2)$ & .47 \\
\hline Site of origin of dissection evidenced in aortic root & $193(39.0)$ & $137(36.8)$ & $56(45.5)$ & .09 \\
\hline Site of origin of dissection evidenced in ascending aorta & $271(54.7)$ & $214(57.5)$ & $57(46.3)$ & .03 \\
\hline Site of origin of dissection evidenced in aortic arch & $19(3.8)$ & $12(3.2)$ & $7(5.7)$ & .28 \\
\hline
\end{tabular}

TABLE 5. Surgical procedures for patients with acute type $A$ aortic dissection

\begin{tabular}{|c|c|c|c|c|}
\hline Variable & $\begin{array}{c}\text { Overall } \\
(n=526)\end{array}$ & $\begin{array}{c}\text { Survived } \\
(\mathrm{n}=394)\end{array}$ & $\begin{array}{c}\text { Dead } \\
(n=132)\end{array}$ & $P$ value \\
\hline Ascending aorta replacement & $463(91.9)$ & $357(93.0)$ & $106(88.3)$ & .11 \\
\hline Aortic root replacement & $135(31.5)$ & $102(31.2)$ & $33(32.7)$ & .78 \\
\hline Right hemiarch replacement & $110(23.2)$ & $87(24.0)$ & $23(20.5)$ & .45 \\
\hline Total arch replacement & $59(12.2)$ & $45(12.1)$ & $14(12.6)$ & .88 \\
\hline Open procedure & $455(91.0)$ & $343(90.5)$ & $112(92.6)$ & .49 \\
\hline Cerebral perfusion & $256(52.2)$ & $193(52.2)$ & $63(52.5)$ & .95 \\
\hline Aortic valve replacement & $111(23.1)$ & $82(22.3)$ & $29(25.4)$ & .49 \\
\hline Aortic valve, root, and ascending aorta replacement & $66(13.9)$ & $45(12.5)$ & $21(18.3)$ & .12 \\
\hline CABG & $78(16.1)$ & $50(13.6)$ & $28(24.1)$ & .007 \\
\hline No. grafts 1 vessel & $45(57.7)$ & $29(58.0)$ & $16(57.1)$ & .94 \\
\hline No. grafts 2 vessel & $15(19.2)$ & $11(22.0)$ & $4(14.3)$ & .41 \\
\hline No. grafts 3 vessel & $11(14.1)$ & $4(8.0)$ & $7(25.0)$ & .05 \\
\hline No. grafts $\geq 4$ vessel & $7(9.0)$ & $6(12.0)$ & $1(3.6)$ & .41 \\
\hline Reoperation & $61(12.8)$ & $47(12.9)$ & $14(12.3)$ & .85 \\
\hline
\end{tabular}

$C A B G$, Coronary artery bypass grafting.

of a new neurologic deficit; left ventricular dysfunction, right ventricular dysfunction, or both at the time of the operation; any pulse deficit; cardiac tamponade; limb ischemia; and the necessity to perform CABG. Independent predictors of surgical mortality are summarized in an age- and sex-adjusted model (Table 6). Model construction proceeded by means of stepwise regression, with consideration for inclusion of historical, presenting, and preoperative risk factors with univariate $P$ values of less than .20. Retention of risk factor variables was determined (with $P<.05$ ) by using the likelihood ratio test. The c-statistic for the final model was 0.72 , with a Hosmer-Lemeshow $\chi^{2}$ statistic of 1.13, a degree of freedom of 6 , and a $P$ value of .98 , and deviance was 65.12 with a degree of freedom of 59 and a $P$ value of .27 .
The mean interval from surgical intervention to death was 364 hours (eg, 327 hours in group I and 522 hours in group II; $P=.21$ ). Among nonsurvivors, death occurred in $13 \%$ within 6 hours, in 34\% within 24 hours, and in $41 \%$ within 48 hours after the beginning of the operation.

\section{Discussion}

Results of operations for acute type A aortic dissection remain suboptimal and corroborate the reported in-hospital mortality rate of $15 \%$ to $30 \% .{ }^{10,16-20}$ Several authors have also described single-center series with markedly lower mortality, even as low as $6.3 \% .^{21}$ In IRAD an overall surgical mortality of $25.1 \%$ was found, despite expert surgical treatment at tertiary care centers for aortic disease. 
TABLE 6. Independent preoperative predictors of operative mortality

\begin{tabular}{lccccc}
\hline Variables at presentation & $\begin{array}{c}\text { Overall type } \\
\text { A \% }\end{array}$ & $\begin{array}{c}\text { Percent among } \\
\text { survivors }\end{array}$ & $\begin{array}{c}\text { Percent among } \\
\text { deaths }\end{array}$ & $\begin{array}{c}\text { Model } \boldsymbol{P} \\
\text { value }\end{array}$ & $\begin{array}{c}\text { Mortality, odds } \\
\text { ratio (95\% Cl) }\end{array}$ \\
\hline History of aortic valve replacement & 4.4 & 3.5 & 7.4 & .02 & $3.12(1.16-8.40)$ \\
Migrating chest pain & 14.2 & 12.1 & 20.5 & .001 & $2.77(1.49-5.15)$ \\
Presenting hypotension as sign of AAD & 17.6 & 13.3 & 30.4 & .02 & $1.95(1.08-3.52)$ \\
Presenting shock or tamponade & 24.7 & 19.5 & 40.7 & .002 & $2.69(1.41-5.11)$ \\
Preoperative cardiac tamponade & 15.7 & 11.8 & 27.6 & .01 & $2.22(1.17-4.22)$ \\
Preoperative limb ischemia & 9.7 & 7.8 & 15.8 & .04 & $2.10(1.00-4.38)$ \\
\hline
\end{tabular}

$\mathrm{Cl}$, Confidence interval; $A A D$, acute type $\mathrm{A}$ aortic dissection.

The IRAD includes surgical results of 18 aortic centers present in 8 different countries, and it is an initial experience in creating such types of registries. The difficulties to project a prospective randomized study associated with the different policies regarding these emergencies in the varying participating centers clearly determines some bias in terms of surgical results. The registry included patients who were medically treated and not operated on for different reasons, such as advanced age and severe comorbid illness, which might not be identical throughout all of the centers. Potentially $121(18.7 \%)$ patients deselected for surgical intervention are enough to influence the overall results, but in IRAD centers the percentage of unstable patients submitted to surgical intervention was higher than the percentage of stable patients undergoing operations (53.5\% vs $46.5 \%$ ), evidencing that not only the lower-risk patients were subjected to operations.

Medical treatment has been previously analyzed in the IRAD ${ }^{22}$ particularly in elderly patients. In this group the in-hospital surgical mortality rate was $45.5 \%$ among patients age 80 to 84 years, and it was $50 \%$ for patients' 85 years of age or older. These data, although they should not represent per se a criterion to exclude patients from undergoing surgical treatment, help physicians in choosing ethical medical treatment in these cases.

The outcome of IRAD patients with type A aortic dissection is the result of operations performed by many surgeons of different ages with varying experience, preferences with regard to operative techniques, variable policies concerning the timing of the operation, and differences in health organizations and hospital structures. Similarly, a mortality of $30 \%$ for acute type A dissection was reported in a 16-center trial in which 180 surgeons were involved. ${ }^{23}$

The nonhomogeneous approach to patients affected by proximal acute aortic dissection explains the difficulties of gathering complete information from 18 international centers. Even if it is possible to analyze 290 clinical variables and their relationship to surgical outcomes, the IRAD has obvious shortcomings in technical surgical data and cannot provide many details, such as site of arterial cannulation, reperfusion after open distal anastomosis, and adjuncts used to reinforce the sutures and possibly obliterate the false channel. Those are of major importance as key factors for good results, as reported by single principal institutions showing a lower mortality rate. ${ }^{21,24}$

IRAD surgical results could be influenced not only by the variability mentioned above but also by the fact that, as already observed, moribund patients admitted at night or on weekends, patients in shock, or patients in extreme conditions are likely to be more frequently operated on by younger surgeons. ${ }^{20}$

In association with technical problems, the operative result is also known to be largely related to the preoperative condition. Preoperative conditions are often the primary cause of postsurgical death ${ }^{1,7,8,25}$ that might even be predicted from presurgical assessment of individual risk conditions. ${ }^{26}$ Differentiation between stable and unstable patients from the IRAD registry demonstrated a significantly higher surgical mortality in unstable than in stable patients (group I: $31.4 \%$ vs group II: $16.7 \%, P<.001$ ), regardless of the type of surgical procedure.

It has commonly been accepted that the interval between onset of symptoms and surgical treatment is closely tied to outcome. The mean time interval from onset of symptoms to surgical intervention for all IRAD patients operated on showed an average of 93 hours for survivors and 37.9 hours for those who died $(P<.001)$. Not surprisingly, this time period was shorter in unstable patients (group I) than in stable patients (group II; 62.9 vs 105.1 hours, $P=.05$ ). Accordingly, the median time interval between confirmed diagnosis and surgical intervention was shorter in group I (unstable patients; 3.4 vs 5.0 hours, $P=.02$ ). A difference from the onset of symptoms to confirmed diagnosis and then to surgical intervention could be associated with a delay in diagnosis or the initiation of medical therapy or, more likely, could be related to comorbid conditions, such as myocardial disorders. In fact, when comparing patients within group I undergoing early aortic repair $(<24$ hours from symptom onset, group Ia) with those having late operations ( $>24$ hours, group Ib), we observed a higher presence of cardiac complications in group $\mathrm{Ib}$, such as myocardial infarction (11.2\% vs $3 \%, P=.02)$ and ECG 


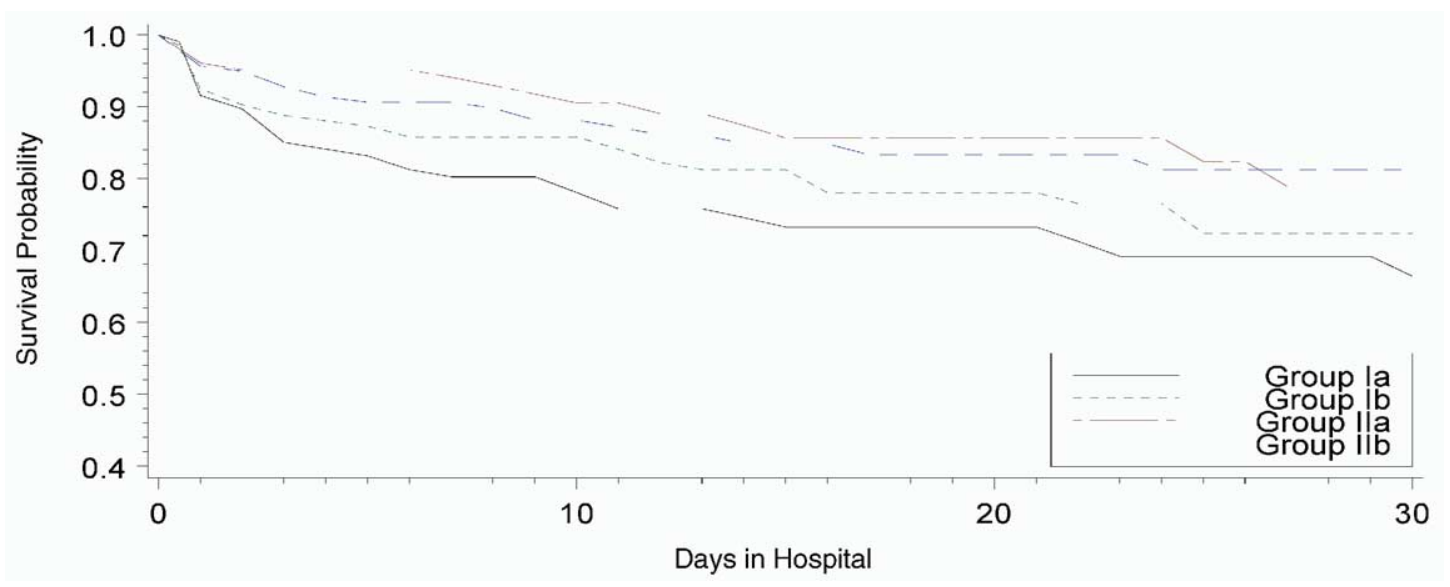

Figure 1. Survival curves for surgical acute type A dissection by stability and hours from symptoms to surgery.

evidence of new Q waves and ST elevations (15.3\% vs 8\%, $P=.12)$. Conversely, unstable patients submitted to surgical intervention within 24 hours (group Ia) presented with more severe preoperative conditions than group $\mathrm{Ib}$, such as pulse deficit (39.8\% vs $28.2 \%, P=.10)$, shock (31.3\% vs $19.8 \%, P=.07)$, preoperative cardiac tamponade $(41.2 \%$ vs $26.1 \%, P=.03$ ), and more coma and altered consciousness (34.0\% vs $14.6 \%, P=.002)$. The comparison of log rank scores for groups Ia and Ib was not significant $(P=.13)$, whereas the comparison for groups Ia and IIa and groups Ia and IIb was statistically positive $(P=.06$ and $P=.02$, respectively), showing a trend in higher mortality for group Ia versus the other 3 risk groups Ib, IIa, and IIb (Figure 1). The presence of major risk factors of mortality will affect outcomes negatively, but this remains, of course, a clear indication for surgical intervention and requires the efforts of undelayed surgical intervention. We also observed a shorter interval time between the onset of symptoms and surgical intervention ( $\leq 12$ hours) in IRAD patients presenting with one or more preoperative independent risk factors of mortality (migrating pain, hypotension, shock, or tamponade at admission or history of aortic valve replacement; $P<.05)$. Moreover, higher significant death rates of group I versus group II were evidenced only within 24 hours from symptoms to surgery (Figure 2). In summary, death differentials for unstable (vs stable) patients in shorter time intervals appear to be caused by defining criteria for clinical instability. The IRAD also reported that normotension at the time of the operation seems to protect from adverse outcomes $(P<.001)$, as does delay to surgical intervention beyond the day of presentation $(P=.05)$. The mortality in patients with surgical treatment delayed beyond 24 hours was much similar to that observed in stable patients $(17.1 \%$ vs $16.7 \%$ ), and concomitantly, a preoperative cardiac catheterization, which was performed in $19 \%$ of cases, was associated with positive outcome $(P=.04)$. It would appear that delaying surgical intervention for any reason improves surgical results. This could be a bias related to the natural selection of the disease but supports the theory that during the management of stabilized patients it can be correct and useful to transfer the patient to a specialist center or avoid operating on him or her during the night or without enough surgical experience. By the way, according to preoperative clinical status, IRAD data show that early surgical intervention is attempted in unstable patients and is associated with a high mortality. The evaluation of the hemodynamic status at the time of the operation reveals a relationship between unstable conditions and a perioperative death rate. Patients with severe hypotension both at admission and surgical intervention have the worst prognosis, with a mortality of 42.3\% $(P<.0001)$.

IRAD data also show that imaging variables are useful in predicting surgical outcomes. A widened mediastinum on chest radiography correlates with higher surgical death $(P=$ $.01)$, and ECG signs of preoperative myocardial ischemiaes $(P=.04)$ or new infarction $(P=.01)$ heralded poor prognosis. This could be related to pre-existing atherosclerosis, extension of the aortic dissection into a coronary artery ostium, or both, which are seen in $14.2 \%$ of patients, or to dynamic flap occlusion at the level of the coronary sinuses, covering the coronary ostia in diastole. Not surprisingly, preoperative left ventricular dysfunction, right ventricular dysfunction, or both are strongly associated with high mortality (both types, $P<.001$ ).

Prior elective cardiac surgery was previously considered a suspected risk factor of dissection ${ }^{19,20}$ and was observed in $17.2 \%$ of IRAD patients. In particular, a history of prior aortic valve replacement was an independent preoperative predictor of operative mortality. In such patients the high mortality is related to specific difficulties of redo operations with total replacement of the sinotubular junction. Creation of a coronary button for coronary reimplantation can be 


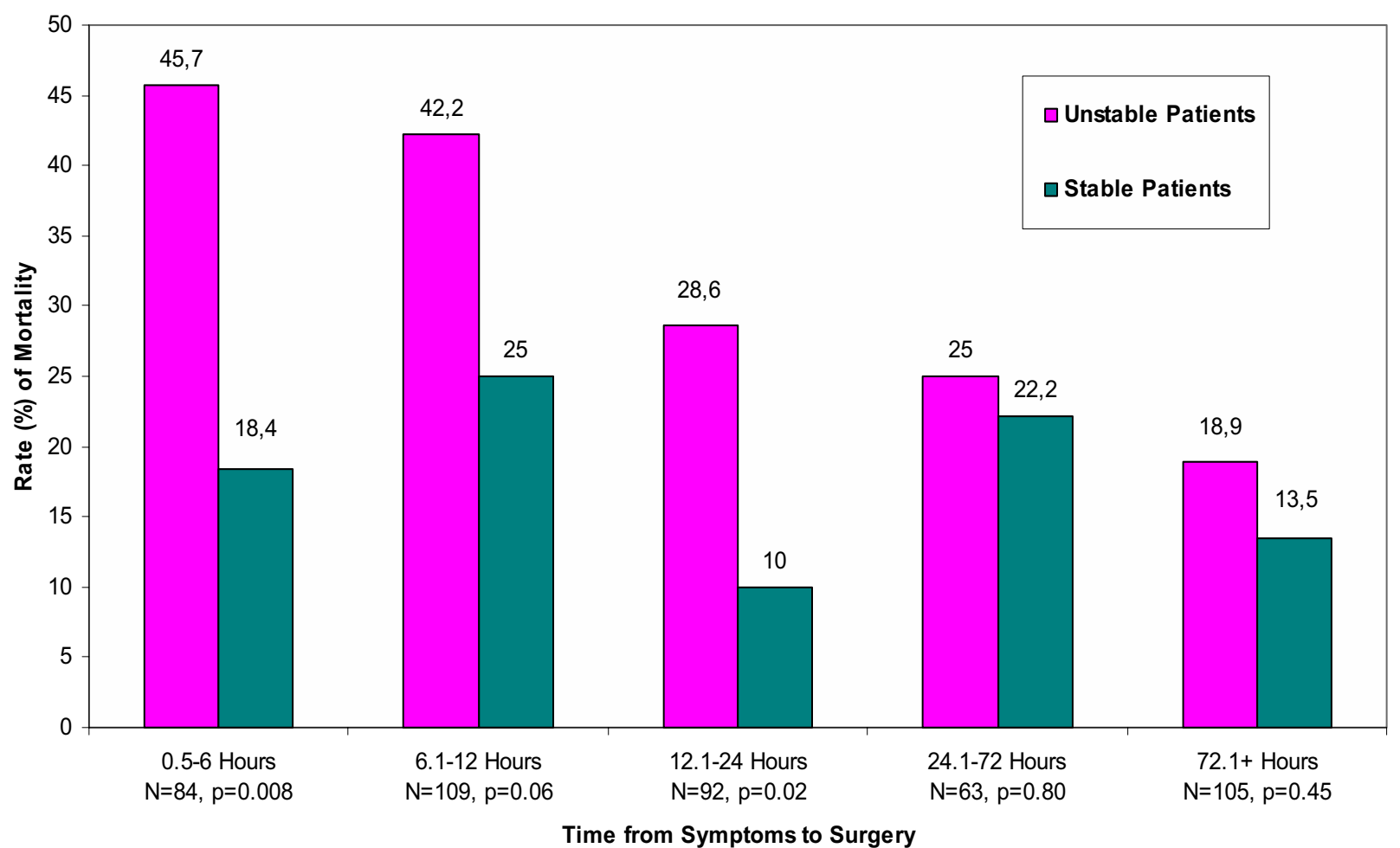

Figure 2. Death rates for unstable patients in group I and group II according to hours from symptoms to surgery. $N$, Patient total; $\boldsymbol{p}, \boldsymbol{P}$ value for contrast in death rates.

difficult because of the lack of tissue after aortic valve prosthesis removal and the presence of calcifications and scar tissue. Although the primary surgical choice seems to be the Bentall-DeBono approach, ${ }^{27}$ sometimes the Cabrol technique $^{28}$ or bridging bypasses are required. The need to perform coronary revascularization is associated with even higher mortality $(P=.007)$. Surgical maneuvers around aortic valve prostheses can also damage the conducting system with the risk of atrioventricular block. Reoperation implies both longer pump and ischemic times. Conversely, in patients with previous cardiac operations, cardiac tamponade and hemodynamic collapse might occur less frequently, probably because of the pericardial adhesions. ${ }^{29,30}$ In patients with relative hemodynamic stability and prior cardiac operations, preoperative angiography might only be appropriate with known coronary artery disease or bypass grafts.

As univariate analysis showed, any pulse deficit and presence of limb ischemia were predictors of increased mortality in all patients $(P=.001$ and $P=.009$, respectively) and in unstable patients $(P=.003$ and $P=.03$, respectively), indicating that ischemic metabolic alterations expose patients to a higher risk of postoperative complications. ${ }^{31}$

\section{Study Limitations}

There is inherent study bias because of the study design of an observational study based mainly on data of tertiary referral centers that might not necessarily be applicable to the total population. Because IRAD is a collection of several participating institutions, the results should not be generalized to all patients submitted to surgical intervention in a single principal institution. In-hospital death was the outcome parameter that was assessed in this registry analysis. Although assessment of mortality is necessary and important to patients, it is not sufficient for full evaluation of patients with type A aortic dissection. One should also take into consideration factors such as surgical technical details, nonfatal adverse events, patient functional status, and resource use. Further studies are needed to address the best surgical approach for evaluating the predictors of long-term survival.

\section{Conclusions}

Even today, in the centers participating in the IRAD, proximal aortic dissection is associated with a $25 \%$ early mortality. Although careful preoperative evaluation of patients with dissection permits assessment of risk and strategic planning for surgical intervention, the perioperative mortality rate was not reduced over the last 20 years. This obser- 
vation might reflect both logistic problems and the inadequacy of the surgical approach and the result of attempted surgical intervention on patients in extreme conditions. Although the time interval between the onset of symptoms and surgical intervention remains a major factor to improve surgical results, IRAD data highlight the notion that a stable clinical status in acute proximal dissection heralds a positive surgical outcome. The IRAD registry provides information regarding baseline preoperative factors that predict increased risk of operative death in patients with acute type A aortic dissection. Although ethical issues are important to consider in patients with high predicted surgical mortality, knowledge and use of these risk factors might help surgeons to justify individual decisions.

\section{References}

1. Miller DC, Mitchell RS, Oyer PE, Stinson EB, Jamieson SW, Shumway NE. Independent determinants of operative mortality for patients with aortic dissections. Circulation. 1984;70(suppl 1):15364.

2. Bachet J, Goudot B, Gilles D, et al. Surgery for acute type A aortic dissection: the Hopital Foch experience (1977-1998). Ann Thorac Surg. 1999;67:2006-9.

3. Heinemann M, Laas J, Jurmann M, Karck M, Borst HG. Surgery extended into the aortic arch in acute type A dissection. Circulation. 1991;84(suppl 3):25-30.

4. Crawford ES, Kirklin JW, Naftel DC, Svensson LG, Coselli JS, Safi HJ. Surgery for acute dissection of ascending aorta. $J$ Thorac Cardiovasc Surg. 1992;104:46-59.

5. Debakey ME, McCollum CH, Crawford ES, et al. Dissection and dissecting aneurysms of the aorta: twenty-year follow-up of five hundred twentyseven patients treated surgically. Surgery. 1982;92:1118-34.

6. Crawford ES, Svensson LG, Coselli JS, Safi HJ, Hess KR. Aortic dissection and dissecting aortic aneurysms. Ann Surg. 1988;208:254-73.

7. Fann JI, Smith JA, Miller DC, et al. Surgical management of aortic dissection during a 30-year period. Circulation. 1995;92(suppl II): II113-21.

8. Ehrlich M, Fang WC, Grabenwoger M, Cartes-Zumelzu F, Wolner F, Havel M. Perioperative risk factors for mortality in patients with acute type A aortic dissection. Circulation. 1998;98(suppl II):II294-8.

9. Hagan PG, Nienaber CA, Isselbacher EM, et al. The International Registry of Acute Aortic Dissection (IRAD): new insights into an old disease. JAMA. 2000;283:897-903.

10. Svensson LG, Crawford ES, Hess KR, Coselli JS, Safi HJ. Dissection of the aorta and dissecting aortic aneurysms: improving early and long-term surgical results. Circulation. 1990;82(suppl IV):IV24-38.

11. Biglioli P, Parolari A, Spirito R, et al. Early and late results of ascending aorta surgery: risk factors for early and late outcome. World J Surg. 1997;21:590-8.

12. Mazzuccotelli JP, Deleuze PH, Baufreton C, et al. Preservation of the aortic valve in acute aortic dissection: long-term echocardiographic assessment and clinical outcome. Ann Thorac Surg. 1993;55:1513-7.

13. Pansini S, Gagliardotto PV, Pompei E, et al. Early and late risk factors in surgical treatment of acute type A aortic dissection. Ann Thorac Surg. 1998;66:779-84.

14. Chirillo F, Marchiori L, Andriolo L, et al. Outcome of 290 patients with aortic dissection, a 12 year multicenter experience. Eur Heart J. 1990;11:311-9.

15. Scholl FG, Coady MA, Davies R, et al. Interval or permanent nonoperative management of acute type A aortic dissection. Arch Surg. 1999; 134:402-6.

16. Haverich A, Miller DC, Scott WC, et al. Acute and chronic aortic dissections: determinants of long-term outcome for operative survivors. Circulation. 1985;72(suppl II):II22-34.
17. Safi HJ, Miller CC, Reardon MJ, et al. Operation for acute and chronic aortic dissection: recent outcome with regard to neurologic deficit and early death. Ann Thorac Surg. 1998;66:402-11.

18. Tan ME, Kelder JC, Morshis W, Schepens MA. Risk stratification in acute type A dissection: proposition for a new scoring system. Ann Thorac Surg. 2001;72:2065-9.

19. Kouchoukos NT, Dougenis D. Surgery of the thoracic aorta. $N$ Engl J Med. 1997;336:1876-88.

20. Bachet J. Acute type A aortic dissection: can we dramatically reduce the surgical mortality? Ann Thorac Surg. 2002;73:701-3.

21. Westaby S, Saito S, Katsumata T. Acute type A dissection: conservative methods provide consistently low mortality. Ann Thorac Surg. 2002;73:707-13.

22. Mehta RH, O'Gara PT, Bossone E, et al. Acute type A aortic dissection in the elderly: clinical characteristics, management, and outcomes in the current era. J Am Coll Cardiol. 2002;40:685-92.

23. Miller DC, Lansman SL, Cameron DE, et al. Aortic Surgery Symposium VIII Discussion: Section 3-Dissection. Ann Thorac Surg. 2002; 74:S1857-63.

24. Bavaria JE, Brinster DR, Gorman RC, et al. Advances in the treatment of acute type A dissection: an integrated approach. Ann Thorac Surg. 2002;74(suppl):S1848-52.

25. Galloway AC, Colvin SB, Grossi EA, et al. Surgical repair of type A aortic dissection by the circulatory arrest: graft inclusion technique in sixty-six patients. J Thorac Cardiovasc Surg. 1993;105:781-90.

26. Mehta RH, Suzuki T, Hagan PG, et al. Predicting death in patients with acute type A aortic dissection. Circulation. 2002;105:200-6.

27. Bentall H, De Bono A. A technique for complete replacement of the ascending aorta. Thorax. 1968;23:338.

28. Cabrol C. Pavie A, Gandjbakhch I, et al. Complete replacement of the ascending aorta with reimplantation of the coronary arteries: new surgical approach. J Thorac Cardiovasc Surg. 1981;81:309-15.

29. Stanger O, Oberwalder P, Dacar D, Knez I, Rigler B. Late dissection of the ascending aorta after previous cardiac surgery: risk, presentation and outcome. Eur J Cardiothoracic Surg. 2002;21:453-8.

30. Gillinov AM, Lytle B, Kaplon RJ, Casselman FP, Blackstone E, Cosgrove DM. Dissection of ascending aorta after previous cardiac surgery: differences in presentation and management. J Thorac Cardiovasc Surg. 1999;117:252-60.

31. Bossone E, Rampoldi V, Nienaber CA, et al. Usefulness of pulse deficit to predict in-hospital complications and mortality in patients with acute type A aortic dissection. Am J Cardiol. 2002;89:851-85.

\section{Appendix 1. The IRAD Investigators}

Co-Principal Investigators: Kim A. Eagle, MD, University of Michigan, Ann Arbor, Mich; Eric M. Isselbacher, MD, Massachusetts General Hospital, Boston, Mass; Christoph A. Nienaber, MD, University of Rostock, Rostock, Germany.

Co-Investigators: Eduardo Bossone, MD, National Research Council, Lecce, Italy; Arturo Evangelista, MD, Hospital General Universitari Vall d'Hebron, Barcelona, Spain; Rosella Fattori, MD, University Hospital S. Orsola, Bologna, Italy; Dan Gilon, MD, Hadassah University Hospital, Jerusalem, Israel; Stuart Hutchison, MD, St Michael's Hospital, Toronto, Ontario, Canada; Alfredo Llovet, MD, Hospital Universitario "12 de Octubre," Madrid, Spain; Rajendra H. Mehta, MD, MS, University of Michigan, Ann Arbor, Mich; Truls Myrmel, MD, Tromsø University Hospital, Troms $\varnothing$, Norway; Patrick O'Gara, MD, Brigham and Women's Hospital, Boston, Mass; Jae K. Oh, MD, Mayo Clinic, Rochester, Minn; Linda A. Pape, MD, University of Massachusetts Hospital, Worcester, Mass; Udo Sechtem, MD, Robert-Bosch Krankenhaus, Stuttgart, Germany; Toru Suzuki, MD, University of Tokyo, Tokyo, Japan; Santi Trimarchi, MD, Istituto Policlinico San Donato, San Donato Milanese, Italy. 


\section{Discussion}

Dr Joseph E. Bavaria (Philadelphia, $\mathrm{Pa}$ ). Dr Trimarchi presents this relatively current report from the International Registry of Acute Dissections, known as IRAD, which analyzes 647 patients with type A dissections. Five hundred twenty-six of these 647 patients had surgical repair of acute type A dissection from 1996 through 2001 at 18 centers worldwide, and these patients form the basis of this report. This is a registry experience and is observational. There is no prospective randomized attempt to compare outcomes on the basis of a change in therapeutics.

The study analyzed 290 clinical variables and related them to outcomes in the 526 surgically treated patients. They defined an unstable group and a stable group fundamentally based on hemodynamics, the presence of malperfusion syndromes, and neurologic presentation. Overall, surgical mortality was $25.1 \%, 31.4 \%$ in the unstable population and $16.7 \%$ in the stable population. Not surprisingly, they identified malperfusion, tamponade, and stroke, with high odds ratios for perioperative mortality rate. Interestingly, they identified prior aortic valve replacement as a serious risk factor but not prior $\mathrm{CABG}$, which might relate to preoperative treatment with warfarin.

So what does this study tell us? Well, it obviously tells us that acute type A dissection is a very serious vascular presentation with a worldwide surgical mortality of more than $25 \%$. This corroborates the public US Food and Drug Administration submission by CryoLife (Marietta, Ga) of their prospective randomized trial in the United States of acute type A dissection, with 174 patients at 20 sites and 56 operating surgeons. The mortality rate of that study was $21 \%$ when presented to the US Food and Drug Administration. It could be argued that this was a stable group in the sense that informed consent had to be obtained from all participants. Dr Trimarchi does not tell us how we can necessarily improve on the overall survival of acute dissection.

In 2002, Dr Jean Bachet asked the following question: Can we dramatically reduce surgical mortality? We might be able to improve results a bit with continually advanced surgical techniques, and recent data suggest we can decrease late reoperations with better technical procedures the first time around. However, Dr Trimarchi's report suggests that we really need to develop more rapid disease recognition, more rapid confirmatory diagnosis, and more rapid transfer. Most importantly, this study might be able to help us understand who not to operate on by defining subsets of patients who have extraordinarily high perioperative mortality rates. Therefore I have 3 questions for Dr Trimarchi.

First, in your study no single independent risk factor would suggest that surgical intervention is either futile or inappropriate. Can you tell us of any combination-I repeat, combination-of risk factors that would result in an odds ratio that would prohibit surgical intervention?

Dr Trimarchi. Thank you for your question, Dr Bavaria. About this issue, up to now we did not analyze the combination of the different risk factors.

Dr Bavaria. That is interesting. That is what we really need to be able to say as to whether we should treat very sick patients with multiple combinations medically or not operate.

Second, should we ever delay surgical intervention?

Dr Trimarchi. This is a very important question. In this study we observed that all patients who had a delay in surgical interven- tion of more than 24 hours showed surgical results similar to those patients categorized as stable (17.9\% vs $16.7 \%)$. In a perverse way we can say that if we delay surgical intervention, we have a better result. Concerning this topic, we conclude that it is related to the natural selection of the disease.

Dr Bavaria. Finally, is there an age, say, 80 or 85 years, at which the outcomes of medical treatment of type A dissection converge with surgical repair?

Thank you very much. This is an excellent article by the IRAD group.

Dr Trimarchi. We already had the opportunity to evaluate patients with advanced age. We had an article that was published in Circulation by Dr Mehta and coauthors that showed that the in-hospital surgical mortality rate among patients aged 80 to 84 years was $45.5 \%$, and for patients with age greater than 85 years, it was $50 \%$. After these indications, we could treat medically all stable patients older than 80 years.

Dr G. Hossein Almassi (Milwaukee, Wis). In your presentation it appeared that the need for coronary bypass is a risk factor.

The question is, are these patients having dissection of their coronary arteries in the setting of an acute myocardial infarction coming to you with dissection, or are these the patients who have native coronary disease to begin with, in which case you are obligated or you might decide to do a couple of extra coronary artery bypasses? I think that makes a difference.

Dr Trimarchi. In these patients we do not know whether CABG was performed for the presence of native coronary atherosclerotic lesions or because of involvement of the coronary arteries in the aortic dissection. Therefore we do not have the right variable regarding the indication to perform a coronary revascularization, and this is a limitation of the registry, even if the necessity of performing a CABG during surgical treatment of acute type A aortic dissection appeared as the unique surgical risk factor.

Dr Steven L. Lansman (New York, NY). I would be curious to know whether you have any data about the size of the ascending aorta or descending aorta at the time of dissection? Also, because previous aortic valve replacement was the most important preoperative risk factor in the multivariate analysis, do you have any information about what size the aorta was at the time of aortic valve replacement and perhaps the incidence of bicuspid aortic valve at that time?

Dr Trimarchi. Thank you, Dr Lansman. We observed that the mean diameter of the aortic annulus was $30 \mathrm{~mm}$, the mean aortic root in all operated patients was $44 \mathrm{~mm}$, the sinotubular junction was $41 \mathrm{~mm}$, the mean ascending aorta was $52 \mathrm{~mm}$, and the mean aortic arch of these patients was $37 \mathrm{~mm}$.

About the bicuspid valve, the incidence of this disease and this pathology in this registry was $4.9 \%$ of cases, and it was not significant in terms of surgical results.

Dr R. Scott Mitchell (Stanford, Calif). Dr Trimarchi, that was a nice presentation. I am not that familiar, but do you include cannulation data in your database to see whether differences in surgical practice — cannulation of axillary arteries versus femoral versus whatever-make a difference?

Dr Trimarchi. Up to now, we do not have these data in this data form. Therefore we are planning to start with a new surgical data form in which we will also include the cannula arterial way perfusion. 
Dr Marc Ruel (Ottawa, Ontario, Canada). I enjoyed your presentation. You showed an inverse relationship between time to operation and survival, which I think most people in the audience would agree is largely due to selection bias.

One question I had that I think is of interest concerns stable patients. What about the dissection about which you get called at 2 AM? Did you look at the relationship between time taken to operate and survival in stable patients?

Dr Trimarchi. Thank you for the question. This is a debated issue that I think is related with the experience of the surgeon on call. All patients that are enrolled, for example, in our institution immediately go to the operating room for surgical intervention. In the IRAD study different surgical results between stable and unstable patients have been shown only within 24 hours from the onset of symptoms, whereas no differential in death rates has been demonstrated after 24 hours. Therefore what we can say is that the natural history of the disease might be similar in the 2 groups, stable or not stable, after 1 day.

Dr Tirone E. David (Toronto, Ontario, Canada). Dr Trimarchi, you reported 526 patients operated on in 18 institutions. Was the mortality related to the number of cases per institution?

Dr Trimarchi. Dr David, we do not have the mortality for each institution. We can say that just in our institution, at the Istituto Policlinico San Donato, it is $16.8 \%$, irrespective of the preoperative clinical conditions. 